ionic mass in atomic weight units, and $V$ is the ionic energy in eV.). When $f \sim 0 \cdot 1$, dissociation and charge transfer predominate, and a predictable atomic spectrum results; while when $0.01<f<$ 0.001 , charge transfer alone results, and the predominant spectrum of the molecular ion and the neutralized atomic ion is seen.

In the experiments of Huggins ${ }^{5}$ and of Ortner and Salim, spectra of the luminescence produced in air by very energetic $\alpha$-particles from radioactive sources were reported. Here $f \sim 0.001$ and the predominant primary radiation appeared to be the $\mathrm{N}_{2}+$ bands, and a few $\mathrm{N}^{+}$lines. Bands of $\mathrm{N}_{2}$ were also observed which were probably due to secondary excitation from the energetic electrons produced in the ion-pair production along $\alpha$-particle tracks. It should therefore be possible to predict the rough spectral composition of the scintillations produced in monatomic and diatomic gases by energetic fast particles from a knowledge of ion energy, gas composition, energy-levels of significan 4 atoms, molecules and ions involved, and a rough idea of the relative oscillator strengths of the possible radiative transitions. Spectroscopic studies of such scintillations are in progress.

This work has been performed with the assistance of Contract $A F^{*} 19(604) 1718$ with the Air Force Cambridge Research Center.

Department of Physics,

R. W. NTCHOLLS

D. Pleiter *

University of Western Ontario, London, Canada.

* Now at the Defence Naval Research Laboratories, Halifax, N.S.

' Conference on aurora and airglow, London, Ontario (1951), Geophysical Research Research Center.

Eggler, C., and Huddleston, C. M., Nucleonics, 14, 34 (1956)

${ }^{3}$ Nicholls, R. W., Amer. J. Phys., 22,59 (1954)

' Fraser, P. A., Amer. J. Phys., 22, 220 (1954).

Hugging, Sir Wm. and Lady, Proc. Roy. Soc., A, Y2, 196 (1903) $76,488(1909) ; 77,130(1906)$. Ortner, G., and Salim, S., Nature 169, 1060 (1952). Meinel, A. B., and Fan, C. Y., Astrophys. J. 115,330 (1952). Fan, C. Y., and Meinel, A. B., ibid., 118, 305 (1953). Fan, C. Y., ibid., 119, 294 (1954); 122, 350 (1955).

${ }^{6}$ Carleton, N. P., Bull. Amer, Phys. Soc., (II), 1, 228 (1956).

\section{Radon Content of the Air}

IN recent years it has become a practice to deduce the radioactivity of the air (that is, its radon content) from the sampling and measurement of the short. lived radon daughter products. This method dates from the beginning of the present century ${ }^{1}$. The unique difference between the early measurements and the recent ones consists in the method of sampling the active deposit of radon; while nowadays deposition on filter paper is almost exclusively used, in the early experiments the transmutation products of radon were collected on the eloctrode by a strong electric field.

As for the filter-paper method, it has been shown by Harley ${ }^{2}$ that even a molecular filter does not retain all airborne dust particles of submicroscopic size. On the other hand, the experimental results of Wilkening ${ }^{3}$ indicate that most of the natural radioactivity in the atmosphere attaches itself to particles having diameters of $0.00 \mathrm{l}-0.04$ micron, and that a predominant grouping of the activity occurs in the vicinity of two particle diameters, namely, 0.009 and 0.018 micron. Hence it is not surprising that the radon values for the atmosphere as deduced from the filter paper method are too low. 'Thus Dawson ${ }^{4}$ finds for January 1950 and on the roof of St. Bartholomew's Hospital in London a mean value of $0.94 \times 10^{-16}$ curie, radon/ml., and for May of the same year $0.28 \times 10^{-16}$ curie $\mathrm{radon} / \mathrm{ml}$. Dawson's values were used very recently as representative of the radioactivity of London's atmosphere. Anderson et $a l^{6}{ }^{6}$ have found by the filter-paper method on the roof of the Physics Department of the Royal Cancer Hospital in London on sunny dry days values as low as $0.02 \times 10^{-16}$ curie radon $/ \mathrm{ml}$.; but by comparing the filter-paper measurements to the direct determination of radon content of the air by the ionization method, they find that filter-paper values correspond only to 2-3 per cent of the true value of radon content. It, is evident that in the free atmosphere radon is not in equilibrium with its daughter products and that variable fractions of the whole amount of the active deposit are attached to the dust or smoke particles and can be collected by the filter paper. We have found the same results for the radon content in closed rooms.

'The experiments were carried out in a laboratory where concentrated radon solutions are prepared. 'The volume of the air in this laboratory is $39 \mathrm{~m}^{3}$. Air samples were examined simultaneously by the Schleicher-Schüll 589 filter-paper and in ionization chambers calibrated by a radium standard solution. About 140 litres of air were drawn during $15 \mathrm{~min}$. with an average speed of $9 \cdot 3$ litre/min. through the filter paper, which was afterwards rolled on a GeigerMüller tube with glass walls penetrable to $\beta$-rays with energy greater than $0.5 \mathrm{MeV}$. An interval of $10 \mathrm{~min}$. was also allowed between the end of the air sampling and the first counts. Measurement of the active deposit was usually prolonged to $2 \mathrm{hr}$. The curves obtained correspond almost exactly to the equilibrium of radium $\mathrm{A}, \mathrm{B}$ and $\mathrm{C}$ during the time of air sampling. The results of four sets of experiments are summarized in Table 1.

Table 1

\begin{tabular}{|c|c|c|}
\hline $10^{-9}$ curie/litre & $N$ (counts/min.) & $N^{*}$ (counts/min.) \\
\hline $\begin{array}{l}1 \cdot 40 \pm 15 \text { per cent } \\
0 \cdot 59 \pm 10 \quad " \\
2 \cdot 80 \pm 10 \quad ", \\
1 \cdot 30 \pm 15 \quad ",\end{array}$ & $\begin{array}{r}25,690 \\
7,060 \\
48,000 \\
12,790\end{array}$ & $\begin{array}{r}18,350 \\
11,980 \\
17,150 \\
9,830\end{array}$ \\
\hline
\end{tabular}

The first column gives the content of radon determined by direct ionization measurement, the second the number $N$ of counts $10 \mathrm{~min}$. after the end of the sampling of the active deposit on the filter paper, and the third the values of the second column reduced to the content of $1 \times 10^{-9}$ curie/litre and designated by $N^{*}$. From the values of $N^{*}$, it is clear that even in closed rooms there is no constant ratio between the active deposit collected on the filter paper and the radon content of the air. From these experiments and the results of Anderson et al..$^{6}$. it is evident that there is no reason for assuming this ratio to be a constant equal to or less than 1 , as is frequently done.

We thank Mr. J. Kočí for technical assistanco.

\section{F. BEHOUNEK}

Institute of Nuclear Physics,

Czechoslovak Academy of Sciences, Prague.

1 Schmid, E., Wiener Ber., 140, 3 (1931).

2 Harley, f. II., Nucleonics, 11, 12 (1953).

${ }_{3}$ Wilkening, M. H., Rev. Sci. Instr., 23, 13 (1952).

a Dawson, K. B., Brit. J. Cancer, 6, 22 (1952).

s"Background Radfation. A Preliminary Litcrature search". U.S. Atomic Fnergy Commission, March 16, 1956.

- Anderson, W., Mayneord. W. V., and 'Turner, R. G., Vature, 174. 424 (1954). 